\title{
Mass spectrometry imaging of glucosinolates in arabidopsis flowers and siliques
}

Article

Accepted Version

Sarsby, J., Towers, M. W., Stain, C., Cramer, R. and Koroleva, O. A. (2012) Mass spectrometry imaging of glucosinolates in arabidopsis flowers and siliques. Phytochemistry, 77. pp. 110118. ISSN 0031-9422 doi:

https://doi.org/10.1016/j.phytochem.2012.01.026 Available at https://centaur.reading.ac.uk/30233/

It is advisable to refer to the publisher's version if you intend to cite from the work. See Guidance on citing.

To link to this article DOI: http://dx.doi.org/10.1016/j.phytochem.2012.01.026

Publisher: Elsevier

All outputs in CentAUR are protected by Intellectual Property Rights law, including copyright law. Copyright and IPR is retained by the creators or other copyright holders. Terms and conditions for use of this material are defined in the End User Agreement.

www.reading.ac.uk/centaur 
Central Archive at the University of Reading

Reading's research outputs online 


\title{
Mass Spectrometry Imaging of Glucosinolates in Arabidopsis Flowers and Siliques
}

\author{
Jos Sarsby, Mark Towers, Chris Stain, Rainer Cramer ${ }^{*}$, Olga Koroleva ${ }^{*}$
}

\section{Graphical abstract}

MALDI-MS imaging in combination with cryo-SEM-EDX analysis demonstrated that glucosinolates are accumulated differentially in specific cells of reproductive organs in Arabidopsis thaliana.
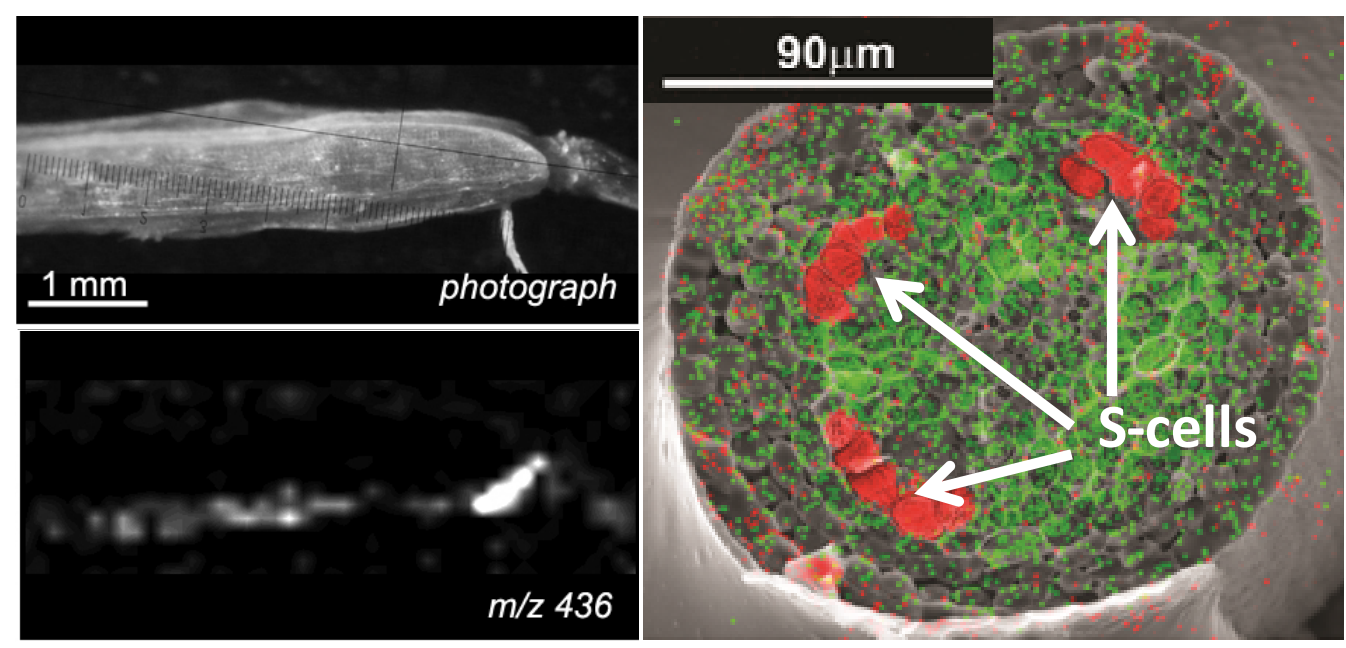


\title{
Mass Spectrometry Imaging of Glucosinolates in Arabidopsis Flowers and Siliques
}

\author{
Jos Sarsby $^{1,6}$, Mark Towers ${ }^{1}$, Chris Stain ${ }^{2}$, Rainer Cramer $^{1,3^{*}}$, Olga A. Koroleva ${ }^{3,4,5^{*}}$ \\ ${ }^{1}$ Department of Chemistry, Whiteknights, Reading, RG6 6AD, UK \\ ${ }^{2}$ Centre for Advanced Microscopy, University of Reading, Whiteknights, Reading, RG6 6AF, UK \\ ${ }^{3}$ BioCentre, University of Reading, Whiteknights, Reading, RG6 6AS, UK \\ ${ }^{4}$ School of Biological Sciences, University of Reading, Whiteknights, Reading, RG6 6AS, UK \\ ${ }^{5}$ Current address: Pursuit Dynamics plc (PDX), Hinchinbrooke, Huntingdon, PE29 6HB \\ ${ }^{6}$ Current address: Physical Sciences of Imaging for Biomedical Sciences, University of \\ Birmingham, Birmingham, B15 2TT \\ * These authors equally contributed to this work and are corresponding authors.
}




\begin{abstract}
Glucosinolates are multi-functional plant secondary metabolites which play a vital role in plant defence and are, as dietary compounds, important to human health and livestock well-being. Knowledge of the tissue-specific regulation of their biosynthesis and accumulation is essential for plant breeding programs. Here, we report that in Arabidopsis thaliana, glucosinolates are accumulated differentially in specific cells of reproductive organs. Using matrix-assisted laser desorption/ionization (MALDI) mass spectrometry imaging (MSI), distribution patterns of three selected compounds, 4-methylsulfinylbutyl (glucoraphanin), indol-3-ylmethyl (glucobrassicin), and 4-benzoyloxybutyl glucosinolates, were mapped in the tissues of whole flower buds, sepals and siliques. The results show that tissue localization patterns of aliphatic glucosinolate glucoraphanin and 4-benzoyloxybutyl glucosinolate were similar, but indole glucosinolate glucobrassicin had different localisation, indicating a possible difference in function. The high resolution images obtained by a complementary approach, cryo-SEM Energy Dispersive X-ray analysis (cryo-SEM-EDX), confirmed increased concentration of sulphur in areas with elevated amounts of glucosinolates, and allowed identifying the cell types implicated in accumulation of glucosinolates. High concentration of sulphur was found in S-cells adjacent to the phloem in pedicels and siliques, indicating the presence of glucosinolates. Moreover, both MALDI MSI and cryo-SEM-EDX analyses indicated accumulation of glucosinolates in cells on the outer surface of the sepals, suggesting that a layer of glucosinolate-accumulating epidermal cells protects the whole of the developing flower, in addition to the S-cells, which protect the phloem. This research demonstrates the high potential of MALDI MSI for understanding the cell-specific compartmentation of plant metabolites and its regulation.
\end{abstract}




\section{Key words:}

Arabidopsis thaliana,

Glucosinolates,

MALDI MSI,

Mass Spectrometry Imaging,

Cryo-SEM-EDX,

S-cells. 


\section{Introduction}

Plants are sessile organisms with advanced chemical defence systems. The characterisation and localisation of endogenous plant defence metabolites can help to understand some crucial aspects of plant defence towards pathogenic and herbivore attack. An important class of plant defence chemicals are glucosinolates, which are sulphur- and nitrogen-rich plant secondary metabolites. They are important chemicals for both plants and animals. Glucosinolate-containing plants are found mostly in the Brassicaceae family and it is these chemicals that cause specific taste and the bitterness in many foods such as horseradish and Brussels sprouts. Glucosinolates are beneficial to the plant because they are part of the plant chemical defence system against insects (Shroff et al., 2008).

Aliphatic glucosinolates have also been shown to be beneficial to human health. Glucosinolates have anticancer properties and their specific hydrolysis products, isothiocyanates in particular, are associated with this trait (Laky et al., 2002; Rose et al., 2000). They also activate enzymes that exhibit antioxidant behaviour and therefore are indirect antioxidants (Jin et al., 2009; Vig et al., 2009). However, high concentrations of glucosinolates in animal feed (such as rapeseed meal) can have a detrimental effect on domestic livestock. Glucosinolates reduce feed intake because of the bitter taste, resulting in a lower growth rate and a smaller overall size of the livestock. Glucosinolates also affect domestic livestock by inhibiting iodine uptake to the thyroid gland and thus reduce thyroid function and growth rate. Animals have different tolerances to glucosinolates and above these tolerances detrimental effects can occur. In extreme cases mortality rates increase (Tripathi and Mishra, 2007).

Glucosinolates are a relatively inactive class of compounds. However, their degradation products are highly reactive and volatile, and there is a wide range of effects caused by them, both beneficial and detrimental for animals (Halkier and Gershenzon, 2006). These degradation products are formed when glucosinolates come into contact with the hydrolyzing enzymes myrosinases ( $\beta$-thioglucosidases). Myrosinases are found in all glucosinolate-containing plants, where they are stored in separate compartments within the cell and only come into contact with glucosinolates when the tissue is damaged. The original "mustard oil bomb" theory (Lüthy and Matile, 1984), which predicts that myrosinase is localised in an inactivated form in the same cell as glucosinolates, has been recently confirmed by our proteomic analysis which indicated enrichment of two myrosinases in the S-cell samples alongside with glucosinolates, suggesting that myrosinases are localised in the same type of cells as glucosinolates, but are segregated within a different subcellular compartment, such as ER or derived vesicles (Koroleva and Cramer, 2011). An initial reaction catalyzed by myrosinase involves the 
hydrolysis of glucosinolate to form a glucose molecule and an aglycone molecule. The aglycone molecule is unstable and degrades further to form different products that are responsible for the biological activities of glucosinolates (Halkier and Gershenzon, 2006). An increasing amount of information regarding the variation of glucosinolate accumulation at the organ-level has become available in recent years (Brown et al., 2003). However, very little is known about the distributions of the different glucosinolates in tissues since no vital staining is available.

We have previously shown that glucosinolates accumulate in S-cells located in the outer periphery of vascular bundles in flower stalks of Arabidopsis plants and proposed their role in phloem protection (Koroleva et al., 2000). Similarly, the position of the S-cells on the distal periphery of the vascular bundles of Arabidopsis leaves (Koroleva et al., 2010) provides the advantages of protecting the nutrientrich phloem from herbivores (Shroff et al., 2008). In addition to the S-cells, it has been found that the cells of the outer margin of the leaf accumulate high amounts of sulphur (Koroleva et al., 2010), corresponding well to a specific localization of an indol glucosinolate (Shroff et al., 2008).

There is a strong interest in altering the levels of specific glucosinolates in crop plants, as some aliphatic glucosinolates have desirable properties while indolic glucosinolates have undesirable properties (Halkier and Gershenzon, 2006). A more in-depth knowledge of the location of specific cells that accumulate and synthesise glucosinolates is required to help crop scientists to modify current varieties and select plants with advantageous properties. Understanding metabolite compartmentation is important for targeting gene expression of the relevant biosynthetic pathway to the correct cell address. For these reasons it is important to know more about where glucosinolates are localised within the plant.

Matrix-assisted laser desorption/ionization (MALDI) mass spectrometry imaging (MSI) is an ideal tool for the analysis of glucosinolates because of its ability to image the distribution of chemical compounds in situ. The accurate mass and isotopic signatures obtained from the MALDI mass spectra allow the identification and characterisation of glucosinolates. Glucosinolates have a distinctive isotopomer signature caused by the relatively high proportion of sulphur, of which $4.21 \%$ is the naturally occurring sulphur isotope ${ }^{34} \mathrm{~S}$. Approximately one fifth of the molecular weight in glucosinolates is in sulphur, and consequently the second and the third isotopologue peaks have similar signal intensity. Analysis of glucosinolates by mass spectrometry is typically performed in the negative ion mode because the sulphate group readily ionises to a negative ion.

The hypothesis for this research is that there is an uneven distribution of specific glucosinolates within Arabidopsis tissues. Our previous research has shown that there are specific sites with high 
concentration of glucosinolates within some Arabidopsis tissues (Koroleva et al., 2000; Koroleva et al., 2010). However, it is still unknown whether there is a consistent difference in localisation of particular glucosinolates in different plant tissues. The aim of the current study was to apply recently developed methods of MALDI MSI to the analysis of Arabidopsis tissue in order to show the distribution of individual glucosinolates, and to confirm the findings of glucosinolate accumulation sites by SEM-EDX imaging of sulphur. 


\section{Results}

\subsection{Direct acquisition of MALDI-MS data from fresh tissues}

\subsubsection{Sepals}

For the sepals, we have found that the outer margin cells produced a very strong signal at m/z 447, corresponding to indolic glucosinolate glucobrassicin, while the peak at m/z 436 (glucoraphanin) had a higher ion signal intensity in the middle of the basal part of the sepal (Fig. 1). These data corroborate with the conclusions of Shroff et al (2008), who found a very similar distribution of these glucosinolates in Arabidopsis leaves, as well as with our previous cryo-SEM-EDX analysis where increased amounts of sulphur were found not only in the mid-lamina but also in the outer margin of the Arabidopsis rosette leaf (Koroleva et al., 2010). In the latter study, the accumulation of sulphur in outer margin cells was found only in mature rosette leaves, suggesting that these cells were different from the S-cells in the vasculature, where accumulation of glucosinolates occurs at the very early developmental stages (Koroleva et al., 2010), and for that reason the outer margin leaf cells were not included into the definition of "S-cells" used for glucosinolate-accumulating cells in phloem parenchyma. Now it can be concluded that the S-cells in vascular bundles and the cells of the outer margin of sepals (Fig. 1) and leaves (Shroff et al., 2008) accumulate glucosinolates belonging to different classes with abundant aliphatic glucosinolate glucoraphanin in the S-cells of the midrib, while indole glucosinolate glucobrassicin is mainly concentrated in the cells of the outer margin of a leaf or a sepal. The peak at m/z 494 (4-benzoyloxybutyl glucosinolate) had a less distinct accumulation pattern, generally following the $\mathrm{m} / \mathrm{z}$ 436-distribution.

\subsubsection{Siliques}

Two types of locations with high glucosinolate content were found in the siliques. Both of these high-glucosinolate location sites appear to be related to the particular anatomical features of the silique. The cells of the first type were localized at the internode, the part of the silique closest to the pedicel (Fig. 2). Strongest signal intensities were detected in this area for ions at $\mathrm{m} / \mathrm{z} 447$ and $\mathrm{m} / \mathrm{z} 436$, which correspond to the indolic glucosinolate glucobrassicin and the aliphatic glucosinolate glucoraphanin, respectively. In addition to this location, ion signals that can be attributed to glucobrassicin and glucoraphanin were present with distributions which correlate to a vascular bundle that runs alongside the silique. The vascular bundles provide the bulk of the nutrients to the developing seeds. 
The second type of location had high signal intensity at $\mathrm{m} / \mathrm{z} 494$, corresponding to the 4benzyloxybutyl glucosinolate, which appears to be distributed alongside the middle of the valve of the silique. However, the distribution of the internal standard, sinigrin has a somewhat similar distribution as 4-benzyloxybutyl glucosinolate, but with a significantly greater intensity. It could be possible that $\mathrm{m} / \mathrm{z} 494$ is present throughout the tissue at very low intensities and can only be seen within regions of overall greater MALDI MSI analyte ion signal intensity on the surface (judged by the signal intensity of the surface-covering standard sinigrin). Therefore, it most likely depends on the topology of the surface area and its signal is higher in areas experiencing higher exposure to the laser beam. Overall, the data corroborates with our previous SEM-EDX data (Koroleva et al., 2010), where glucosinolates were shown to accumulate on the periphery of vascular bundles and in the epidermal cells of the outer margin of the leaf.

\subsubsection{Flower buds}

For the flower buds we have found that there is a different distribution for each of the above $\mathrm{m} / \mathrm{z}$ values (Fig. 3). An ion signal at $\mathrm{m} / \mathrm{z} 436$ which corresponds to the glucoraphanin was found mainly in sepals where the strongest signal occurs at the base of the sepal and in the distal parts of the petals. The signal produced from the ion at $\mathrm{m} / \mathrm{z}$ 494, which can be attributed to 4-bensyloxybutyl glucosinolate, shows a relatively even distribution throughout the flower bud similar to the standard sinigrin. The ion signal at m/z 447 (glucobrassicin) signal mainly arises from the sepals as indicated by the higher intensities observed from the regions where petals are still covered by the sepals, and the flower bud base/pedicel. A very faint signal is obtained from the petals where it shows to be present in the cells on the periphery. These data indicate that in general the patterns of distribution of glucosinolates in sepals and petals are similar to the distributions of glucosinolates in the leaves described by Shroff et al (2008). The patterns are consistent with our above-mentioned MALDI MSI data for the distribution of glucosinolates in sepals.

Representative mass spectra of the imaged glucosinolates sinigrin (m/z 358), glucoraphanin (m/z 436), glucobrassicin (m/z 447) and 4-benzoyloxybutyl glucosinolate (m/z 494) are shown on Fig. 4. The insert on the Fig. 4A shows the theoretical isotopologue distribution for sinigrin.

\subsection{Imaging of the sulphur distribution by cryo-SEM-EDX for identification of sulphur-rich} regions in pedicels, sepals and siliques 
Following our previous study of the glucosinolate-rich S-cells of the flower stalk and leaf tissues, we investigated the occurrence of these cells in plant reproductive organs. Using the cryo-SEM/EDX technique as previously described (Koroleva et al., 2010), the sulphur distribution was mapped on cryofractured flower buds, sepals and young siliques of Arabidopsis plants (Fig. 5). Again, we have found small groups of cells in vascular bundles with very high sulphur content (Fig. 5 D, F, I, J, L). The location in the abaxial part of the vascular bundles and appearance of these cells are similar to the Scells on cryo-sections of flower stalks and leaves described earlier (Koroleva et al., 2010).

\subsubsection{Pedicels}

SEM imaging of the cryo-sections of pedicels revealed very similar anatomy to the flower stalks. The sulphur distribution maps unequivocally showed localization of S-cells on the periphery of the vascular bundles (Fig. $\mathbf{5} \mathbf{D}, \mathbf{J}$ ), very similar to that previously found in the flower stalks (Koroleva et al., 2010).

\subsubsection{Sepals}

Our results show that in the top part of the sepals, the outer epidermal cells (on the abaxial surface) possess a higher content of sulphur than mesophyll cells or epidermal cells on the adaxial surface cells (Fig. $5 \mathbf{~ E , ~ K}$ ), while the accumulation of potassium was high in all epidermal and mesophyll cells on the same cryo-fractured surface of the top part of the sepal (Fig. $\mathbf{5} \mathbf{~ H , ~ K}$ ).

\subsubsection{Siliques}

SEM imaging of the cryo-sections of siliques revealed two symmetric sites with high sulphur signals on the periphery of the vascular bundles in the replum area (Fig. 5 C, F, I). Both the location of the cells in the phloem parenchyma area, and their appearance as a group of several large cells are identical to the S-cells earlier described in flower stalks and leaves of Arabidopsis (Koroleva et al., 2010), and in the vascular bundles of pedicels of the current study. Since the S-cells were found in the vascular bundles of flower stalks and leaves of Arabidopsis (Koroleva et al., 2000, 2010), and in the vascular bundles of siliques and flower pedicels of the current study, we conclude that all major vascular bundles in Arabidopsis tissues contain glucosinolate-rich S-cells, characterised by a high content of sulphur and specific anatomy. 
In some siliques, higher concentration of sulphur was found not only in the vascular bundles of the replum, but also in the epidermal cells of the valves (Fig. $5 \mathbf{~ L}$ ). The accumulation of high sulphur concentration was previously observed in epidermal cells of the outer margin of the mature leaves (Koroleva et al., 2010), and in sepals described in the current study. 


\section{Discussion}

Our results demonstrate an uneven distribution of ion signals that can be attributed to glucosinolates in the reproductive tissues of Arabidopsis, and a difference in patterns between these. The major achievements of this study include the successful imaging of Arabidopsis flower bud, sepal and silique tissue to show the specific distribution of three common glucosinolates, 4-methylsulfinylbutyl (glucoraphanin), indol-3-ylmethyl (glucobrassicin), and 4-benzoyloxybutyl glucosinolates.

The MALDI MSI images obtained of sepal, silique and flower bud clearly show that the aliphatic, aromatic and indolic glucosinolates detected here, accumulate independently of each other. Tissue regions in the siliques and the sepals where these glucosinolates are present in higher concentrations are identified. All data obtained by MALDI MSI in this report are consistent with complementary high resolution data from cryo-SEM-EDX analysis, which confirms the presence of sulphur in areas identified by MALDI MSI, further asserting that the detected ions were glucosinolates. By using SEM it was possible to identify the cell types that contained high amounts of sulphur and glucosinolates. We have previously performed mass-balance calculations for S-cells in the Arabidopsis flower stalks and demonstrated that glucosinolates account for $84 \%$ of total sulphur (Koroleva et al., 2000). Though the presence of elemental sulphur has been previously shown to occur in plant tissues, it is insoluble in water and therefore is likely to be in a form of solid deposition on the cell walls (Cooper et al., 1996), rather than more or less uniformly distributed SEM-EDX pattern through the vacuole observed in Figure 5 of our study.

The types of cells in the reproductive organ tissues of Arabidopsis that were found to contain glucosinolates by MALDI MSI imaging, match the cell types previously identified in leaves and flower stalks of Arabidopsis by other means (Koroleva et al., 2010). S-cells, which contain high levels of glucosinolates, were identified at the phloem periphery of all major vascular bundles. Previously, we used MALDI-TOF MS for the identification of GSL in S-cell extracts by their accurate mass and sulphur isotopic signature, in S-cell samples (approximately 1-2 $\mathrm{nl}$ ), taken from a flower stalk by glass capillary and immediately expelled into $10 \mu \mathrm{l}$ of methanol, mixed 1:1 with matrix and spotted at 1 $\mu \mathrm{l} / \mathrm{spot}$ on the MALDI target plate. The S-cell spectra were dominated by a high intensity negative ion peak of m/z 436.1, corresponding to 4-methylsulphinylbutyl GSL (glucoraphanin) (Fig 6, reproduced from: Koroleva et al, 2010, Plant Journal, 64: 456). All of the analysed samples also had relatively strong negative ion signals at $\mathrm{m} / \mathrm{z} 422.0$ and 492.1, corresponding to 3-methylsulfinylpropyl (glucoiberin) and 8-methylsulfinyloctyl (glucohirsutin) GSL, respectively. Lower signal intensities were 
found for $\mathrm{m} / \mathrm{z}$ 447.1, 450.1, 477.1 and 478.1, corresponding to 3-indolylmethyl (glucobrassicin), 5methylsulfinylpentyl (glucoalyssin), 4-methoxyindol-3-ylmethyl (methyoxyglucobrassicin) and 7methylsulfinylheptyl (glucosiberin) GSL, respectively (Koroleva et al., 2010). Our current results indicate very similar profiles for cells in the proximity of vascular bundles, including novel finding that S-cells are not only present in leaves and flower stalks, but also in pedicels and siliques - plant reproductive organs.

The presence of S-cells in pedicels and siliques is a new discovery and further supports the postulate that glucosinolates form an important part of the plant defence system. The data obtained by both MALDI MSI and cryo-SEM-EDX, which show accumulation of sulphur/glucosinolates in the epidermal cells of the sepals, also support this postulate. Sepals cover the entire developing flower bud, and thus protect the flower bud as it was shown by Shroff et al (2008) that tissues with higher concentrations of glucosinolates are less likely to be consumed by herbivores. So far S-cells rich in glucosinolates were found on the phloem periphery of the vascular bundles in Arabidopsis flower stalks, leaves, flower pedicels and siliques. These cells have a very peculiar anatomy and show early signs of apoptosis (Koroleva et al., 2000, 2010). Proteomic analysis revealed a very specific proteome with abundant myrosinases TGG1 and TGG 2 in the S-cells of the flower stalk (Koroleva and Cramer, 2011), suggesting that glucosinolates and myrosinases are localised in the same cells, but in different subcellular compartments.

Current challenges in the application of MALDI MSI include variations in the sample topology due to unavoidable natural variations of the sample and the laser ablation, potential artefacts caused by tissue damage, low ion counts caused by a low concentration of the metabolite, insufficient or obscured ion signals for MS/MS identification, and in general, overlapping ion signals of other compounds. For example, in plant tissues, compounds such as a flavanoids, have been identified to be present at the same mass as some glucosinolates (Seyer et al., 2010). We have used isotopologue profiles (Fig. 4) and the presence of characteristic fragment ions in tissue sample extracts analysed by LC-MS to confirm the identity of the putative glucosinolate signals (data not shown).

To overcome the problems associated with the topology of plant samples, we have tested two different approaches of sample preparation, mounting of either fresh tissues or paper blots of tissue prints for MALDI MSI analysis. Both techniques have their advantages and disadvantages for being used with plant tissue. Overall, we have found that the best spatial resolutions and signal intensity was achieved by direct MALDI MSI of the fresh tissues. However, the most common artefact we observed 
was that the uneven surface of the investigated tissues can cause a shift in the $\mathrm{m} / \mathrm{z}$ coordinate for the maximum ion signal intensity. Although we were also able to demonstrate that glucosinolates can be analyzed from tissue prints on blotting paper, only from a few areas glucosinolate ion signals were detected and the signal intensity and spatial resolution was very low, resulting in no conclusive distributions of glucosinolates (data not shown).

Using two parallel techniques, MALDI MSI of the most abundant glucosinolates and cryo-SEMEDX imaging of sulphur, allowed us to cross-validate the results of each technique. MALDI MSI has the advantage of accurate mass measurement, resolving isotopologue profiles and analysing characteristic fragment ions. The spatial resolution of a typical MALDI MS instrument, however, is 50$100 \mu \mathrm{m}$ and therefore not sufficient for true single-cell resolution. On the other hand, cryo-SEM-EDX imaging offers a spatial resolution of less than $5 \mu \mathrm{m}$ for the localisation of elements on tissue fractures. In our study it allowed identifying cells with higher sulphur content, which correlates with higher concentration of glucosinolates, because of the presence of two or more atoms of sulphur in each glucosinolate molecule (Koroleva et al, 2010). Although SEM-EDX can reveal the distribution of a marker element such as sulphur, it is not able to identify a specific chemical compound, which harbours this element. Thus, the information obtained from MALDI MSI and SEM-EDX was complementary. SEM-EDX indicated the position of S-cells containing high levels of sulphur while the corresponding tissue areas analysed by MALDI MSI indicated the presences of particular glucosinolates.

The data from the two approaches were in good agreement with respect to the localisation of sulphur and the sulphur-containing glucosinolates. Thus it is possible to make the conclusion that the sulphur detected by SEM-EDX is at least partially due to the glucosinolates detected by MALDI MSI.

\section{Concluding Remarks}

Overall, the current study has delivered novel insights into the localisation of three individual glucosinolates in sepal, flower bud and silique tissues. The results are consistent with previous publications (Shroff et al., 2008, Koroleva et al., 2000, 2010) on the non-uniform distribution of glucosinolates in Arabidopsis tissues. We confirmed that phloem-associated S-cells, earlier discovered in the flower stalk and leaves of Arabidopsis, also are present in the siliques. This study shows that MALDI MSI has the capabilities for the in situ imaging of glucosinolates in intact plant tissues. 


\section{Experimental}

\subsection{General Experimental Procedures.}

MALDI MSI was performed using Ultraflex Tof/Tof (Bruker UK, Coventry, UK). Cryo- Scanning Electron Microscopy Energy Dispersive X-ray analysis was performed using Quanta 600F SEM (FEI UK, Cambridge, UK). All chemicals were purchased from Sigma ((Sigma, Poole, UK) ), unless stated otherwise.

\subsection{Preparation of freshly harvested plant tissues for direct MALDI MSI}

Arabidopsis thaliana plants were grown in the greenhouse as previously described (Koroleva et al., 2010). Flower buds, sepals and siliques were harvested and mounted as follows. Flower buds were removed from the whole plant with a sharp blade and carefully mounted onto conductive tape. Sepals were removed from a flower bud and then arranged on conductive tape so that the exposed side of the sepals were available for analysis. Siliques were prepared by slicing the silique longitudinally along the silique main veins taking care not to damage them. The siliques were then placed on conductive tape insuring that the exposed edge was oriented upwards. Matrix was prepared by dissolving 9aminoacridine (9-AA) in $70 \%$ Ethanol (aq) to a concentration of $7.5 \mathrm{mg} / \mathrm{mL}$. Sinigrin was added to the matrix as an internal standard to a final concentration of $1 \mathrm{mM}$. The tissues were sprayed with the 9-AA and sinigrin solution by a TLC sprayer, then left to dry and mounted onto a MALDI target plate.

\subsection{MALDI MSI - data acquisition and processing}

To perform MALDI MSI, sample rasters were created using an in-house written program, which was developed for previous study (Towers et al, 2010). The software was written in Perl and has been named the Perl Imaging Mass Spectrometry Software suite (PIMSS) and is available upon request. The PIMSS software creates sample rasters in the form of .XEO files which can be used as target plate plans with an Ultraflex Tof/Tof (Bruker UK, Coventry, UK) instrument. Sampling positions were $50 \mu \mathrm{m}$ apart, the laser focus was ca. $50 \mu \mathrm{m}$ and data from 20 laser shots were acquired at each position using the automated AutoXecute routine of FlexControl III (Bruker UK). Before data acquisition the instrument was calibrated in negative ion mode in the low-mass range, by using four deoxynucleotide triphosphates (dNTPs), and the commercially available glucosinolate sinigrin, as reference masses. A sample of dNTP solution $(10 \mathrm{mM})$ and sinigrin $(1 \mathrm{mM})$ was placed on the support plate near a tissue sample to be 
analysed, and spectra were acquired in the negative ion mode using delayed extraction and an ion acceleration potential difference of $20.0 \mathrm{kV}$.

After data acquisition the resulting spectra were combined and transformed using PIMSS for analysis in BioMap (Novartis, Basel, Switzerland). After visual examination of the complete imaging data, masses with distributions of interest were selected for individual analysis. PIMSS allows for the production of images with a reduced mass range and a localized realignment of a specified $\mathrm{m} / \mathrm{z}$. This allows for compensation of variation in the accurate mass measurement for a given peak induced by the sample morphology and any time-related calibration drifts. For localized realignment the approximate $\mathrm{m} / \mathrm{z}$ value of the peak of interest is entered into PIMSS with a peak alignment tolerance of 0.5 Da. For each individual spectrum the highest intensity value within the specified range is identified, these are then aligned to the data point with the greatest frequency of highest intensities. An optional cut-off value can be set as a percentage of the highest intensity recorded within the range for the complete data set. Values below the cut-off value are not aligned or used for the calculation of the alignment data point. A cut-off value of $10 \%$ was used for the production of the images presented here.

\subsection{Cryo-SEM}

The X-ray imaging of the elemental distribution was performed on cryo-fractures of Arabidopsis tissues as previously described (Koroleva et al., 2010). Briefly, flowers and siliques were mounted in a specimen holder using a mixture of colloidal graphite and low temperature adhesive. The tissue was

frozen in a liquid nitrogen slush and the tissue fractured under vacuum to expose the internal contents of the cells. An SEM image was taken and afterwards X-Ray maps of the distribution of sulphur and potassium were collected with an accelerating voltage of $15 \mathrm{kV}$ using a Quanta 600F SEM (FEI UK, Cambridge, UK). Maps of the elements were superimposed on the SEM image using INCA X-ray analysis software (Oxford Instruments, Abingdon, UK).

\section{Acknowledgements}

We would like to thank the British Mass Spectrometry Society (BMSS) for their support through a BMSS summer studentship to J.S., and acknowledge the BioCentre at the University of Reading for access to the MALDI-TOF MS instrument. 


\section{Figure legends}

Figure 1. Photograph of a sepal separated from an Arabidopsis flower (top left) with five corresponding MALDI MSI images. The basal part of the sepal is on the left side. Three MALDI MSI images show the distributions of three specific $\mathrm{m} / \mathrm{z}$ values that can be attributed to three native glucosinolates: glucoraphanin (m/z 436), glucobrassicin (m/z 447) and 4-benzoyloxybutyl glucosinolate

( $\mathrm{m} / \mathrm{z}$ 494), respectively. The bottom two MALDI MSI images show maps of the distribution of the applied glucosinolate standard sinigrin (m/z 358) and the distribution of the 9-AA matrix ion (m/z 193).

Figure 2. Photograph of an Arabidopsis silique (top left) with five corresponding MALDI MSI images. Three MALDI MSI images show the distributions of three specific $\mathrm{m} / \mathrm{z}$ values that can be attributed to three native glucosinolates: glucoraphanin $(\mathrm{m} / \mathrm{z} 436)$, glucobrassicin $(\mathrm{m} / \mathrm{z} 447)$ and 4benzoyloxybutyl glucosinolate (m/z 494), respectively. The bottom two MALDI MSI images show maps of the distribution of the applied glucosinolate standard sinigrin (m/z 358) and the distribution of the 9-AA matrix ion $(\mathrm{m} / \mathrm{z} 193)$.

Figure 3. Photograph of an Arabidopsis flower bud (top left) with five corresponding MALDI MSI images. Three MALDI MSI images show the distributions of three specific $\mathrm{m} / \mathrm{z}$ values that can be attributed to three native glucosinolates: glucoraphanin (m/z 436), glucobrassicin (m/z 447) and 4benzoyloxybutyl glucosinolate (m/z 494), respectively. The bottom two MALDI MSI images show maps of the distribution of the applied glucosinolate standard sinigrin (m/z 358) and the distribution of the 9-AA matrix ion (m/z 193).

Figure 4. Representative mass spectra of the imaged glucosinolates. A, sinigrin (m/z 358) with an inset showing the theoretical isotopologue distribution; B, glucoraphanin (m/z 436); C, glucobrassicin (m/z 447); D, 4-benzoyloxybutyl glucosinolate (m/z 494).

Figure 5. Distribution of sulphur analysed by EDX on the surface of frozen Arabidopsis (ecotype Col-0) tissues transversely fractured on a cryo stage. Distinct sites of accumulation of sulphur were found on the cross-fracture surfaces of a pedicel $(\mathbf{A}, \mathbf{D}, \mathbf{G}, \mathbf{J})$ and a sepal $(\mathbf{B}, \mathbf{E}, \mathbf{H}, \mathbf{K})$, which are shown in red colour on the X-ray maps $(\mathbf{D}, \mathbf{E})$ and on the composite images $(\mathbf{J}, \mathbf{K})$. Potassium was more evenly 
distributed in the pedicel and sepal tissues, shown in green colour on the X-ray maps $(\mathbf{G}, \mathbf{H})$ and on the composite images ( $\mathbf{J}, \mathbf{K})$.

For the siliques (C, F, I, L), SEM images were overlaid by the maps of sulphur distribution (in red colour): F, higher magnification of the replum area, outlined by the smaller yellow square in the top part of the whole silique image of $\mathbf{C}$. I, higher magnification of the other replum outlined by the larger yellow square in the bottom part of image $\mathbf{C}$. $\mathbf{L}$, in some siliques, a higher concentration of sulphur was found not only in the vascular bundles of the replum, but also in the epidermal cells of the valves.

Figure 6. MALDI-TOF spectra of S-cell sample.

Reproduced from: Koroleva et al, 2010, Plant Journal, 64: 456.

A, spectrum 420-450 Da showing most abundant GSL masses in S-cell sample from flower stalk (ecotype Col-0). B, spectra 300- 440 Da; C, spectra 420-650 Da from the same sample. 


\section{Tables}

Table 1. List of detected MALDI MSI ions that can be attributed to specific glucosinolates in three tissue types.

\begin{tabular}{|c|c|c|c|c|c|c|c|c|c|}
\hline \multirow[t]{2}{*}{ Compound } & \multirow{2}{*}{$\begin{array}{c}\text { Mass to charge ratio } \\
(\mathrm{m} / \mathrm{z}) \text { in negative ion } \\
\text { mode }\end{array}$} & \multicolumn{3}{|c|}{$\begin{array}{l}\text { Detection in three } \\
\text { sepals analysed by } \\
\text { MALDI MSI }\end{array}$} & \multicolumn{2}{|c|}{$\begin{array}{l}\text { Detection in two } \\
\text { siliques analysed by } \\
\text { MALDI MSI }\end{array}$} & \multicolumn{3}{|c|}{$\begin{array}{l}\text { Detection in three } \\
\text { flower buds analysed } \\
\text { by MALDI MSI }\end{array}$} \\
\hline & & 1 & 2 & 3 & 1 & 2 & 1 & 2 & 3 \\
\hline 9-AA (matrix) & 193 & + & + & + & + & + & + & + & + \\
\hline Sinigrin (standard) & 358 & + & + & + & + & + & + & + & + \\
\hline Glucoiberin & 422 & - & - & + & - & - & + & + & + \\
\hline Glucoraphanin & 436 & + & + & + & + & + & + & + & + \\
\hline Glucobrassicin & 447 & + & + & + & + & + & + & + & + \\
\hline Glucohirsutin & 492 & - & - & - & + & + & - & - & - \\
\hline $\begin{array}{c}\text { 4-benzyloxybutyl } \\
\text { glucosinolate }\end{array}$ & 494 & + & + & + & - & + & + & + & + \\
\hline
\end{tabular}

' + ' denotes that the ion was detected and '-' denotes that the ion was not detected. Ions corresponding to the 9-aminoacridine matrix (m/z 193) and the glucosinolate sinigrin ( $\mathrm{m} / \mathrm{z} 358)$ were always detected as both compounds were evenly sprayed onto the surface of the tissues. 


\section{References}

Brown PD, Tokuhisa JG, Reichelt M, Gershenzon J. 2003. Variation of glucosinolate accumulation among different organs and developmental stages of Arabidopsis thaliana. Phytochemistry 62, 471-481.

Bunch J, Clench MR, Richards DS. 2004. Determination of pharmaceutical compounds in skin by imaging matrix-assisted laser desorption/ionisation mass spectrometry. Rapid Commun Mass Spectrom 18, 3051-3060.

Cooper RM, Resende MLV, Flood J, Rowan MG, Beale MH, Potter U. 1996. Detection and cellular localization of elemental sulphur in disease-resistant genotypes of Theobroma cacao. Nature 379, 159 - 162.

Fahey JW, Zalcmann AT, Talalay P. 2001. The chemical diversity and distribution of glucosinolates and isothiocyanates among plants. Phytochemistry 56, 5-51.

Halkier BA, Gershenzon J. 2006. Biology and Biochemistry of Glucosinolates. Annual Review of Plant Biology 57, 303-333.

Jin J, Koroleva OA, Gibson T, Swanston J, Magan J, Zhang Y, Rowland IR, Wagstaff C. 2009. Analysis of phytochemical composition and chemoprotective capacity of rocket (Eruca sativa and Diplotaxis tenuifolia) leafy salad following cultivation in different environments. J Agric Food Chem 57, 5227-5234.

Koroleva OA, Cramer R. 2011. Single-cell proteomic analysis of glucosinolate-rich S-cells in Arabidopsis thaliana. Methods 54, 413-423.

Koroleva OA, Davies A, Deeken R, Thorpe MR, Tomos AD, Hedrich R. 2000. Identification of a new glucosinolate-rich cell type in Arabidopsis flower stalk. Plant Physiol 124, 599-608.

Koroleva OA, Gibson TM, Cramer R, Stain C. 2010. Glucosinolate-accumulating S-cells in Arabidopsis leaves and flower stalks undergo programmed cell death at early stages of differentiation. Plant J. 64, 456-469.

Laky B, Knasmüller S, Gminski R, Mersch-Sundermann V, Scharf G, Verkerk R, Freywald C, Uhl M, Kassie F. 2002. Protective effects of Brussels sprouts towards B[a]P-induced DNA damage: a model study with the single-cell gel electrophoresis (SCGE)/Hep G2 assay. Food and Chemical Toxicology 40, 1077-1083.

Luthy B, Matile P. 1984. The mustard oil bomb: rectified analysis of the subcellular organization of the myrosinase system. Biochem Physiol Pflanz 179, 5-12.

Reichelt M, Brown PD, Schneider B, Oldham NJ, Stauber E, Tokuhisa J, Kliebenstein DJ, Mitchell-Olds T, Gershenzon J. 2002. Benzoic acid glucosinolate esters and other glucosinolates from Arabidopsis thaliana. Phytochemistry 59, 663-671.

Rose P, Faulkner K, Williamson G, Mithen R. 2000. 7-Methylsulfinylheptyl and 8methylsulfinyloctyl isothiocyanates from watercress are potent inducers of phase II enzymes. Carcinogenesis 21, 1983-1988.

Seyer A, Einhorn J, Brunelle A, Laprevote O. 2010. Localization of flavonoids in seeds by cluster time-of-flight secondary ion mass spectrometry imaging. Anal Chem 82, 2326-2333.

Shroff R, Vergara F, Muck A, Svatos A, Gershenzon J. 2008. Nonuniform distribution of glucosinolates in Arabidopsis thaliana leaves has important consequences for plant defense. Proc Natl Acad Sci U S A 105, 6196-6201.

Towers MW, McKendrick JE, Cramer R. 2010. Introduction of 4-chloro-alpha-cyanocinnamic acid liquid matrices for high sensitivity UV-MALDI MS. J Proteome Res. 9,1931-1940. 
Tripathi MK, Mishra AS. 2007. Glucosinolates in animal nutrition: A review. Animal Feed Science and Technology 132, 1-27.

Vig AP, Rampal G, Thind TS, Arora S. 2009. Bio-protective effects of glucosinolates - A review. LWT - Food Science and Technology 42, 1561-1572. 
Figure 1.
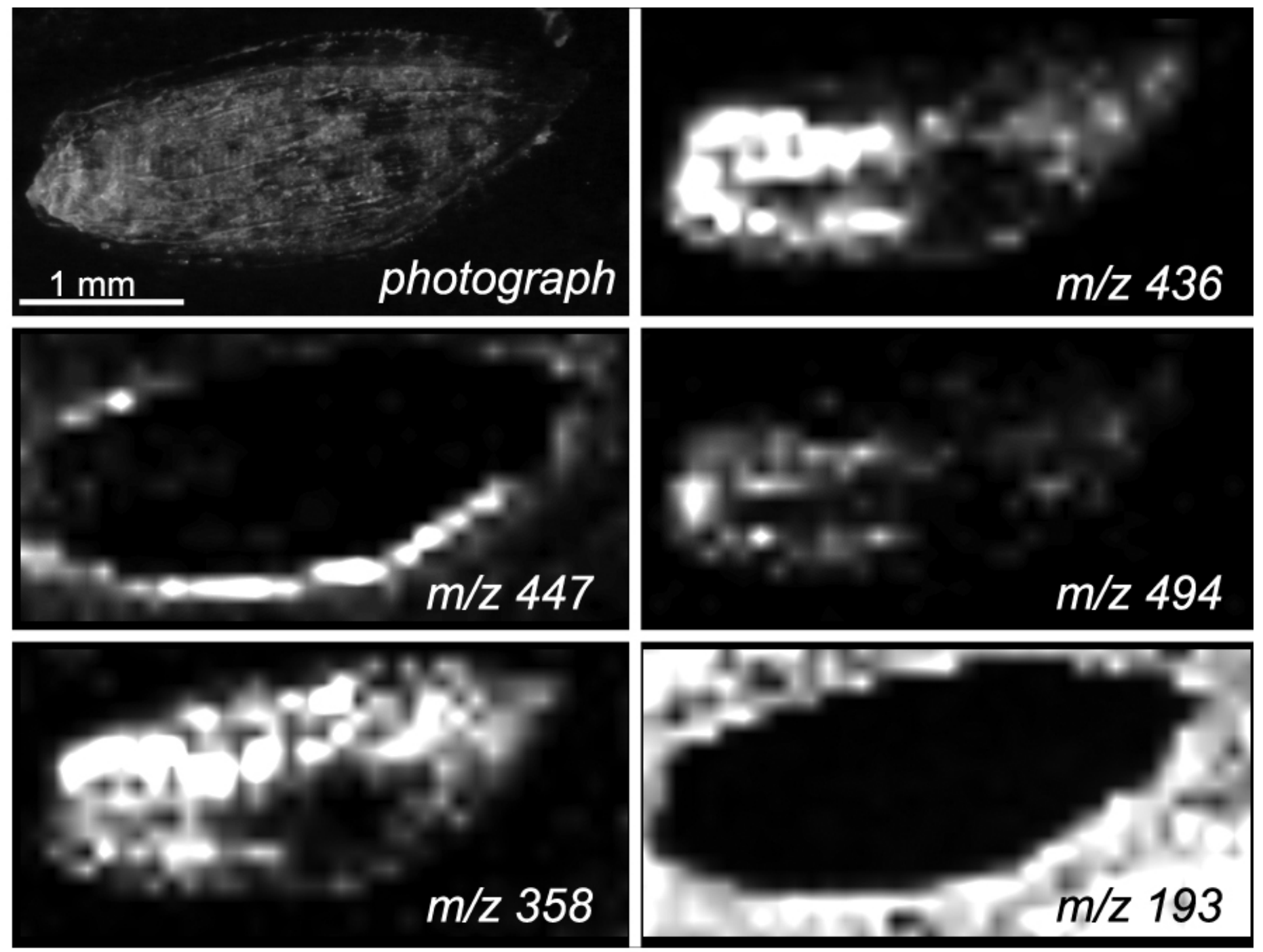
Figure 2.
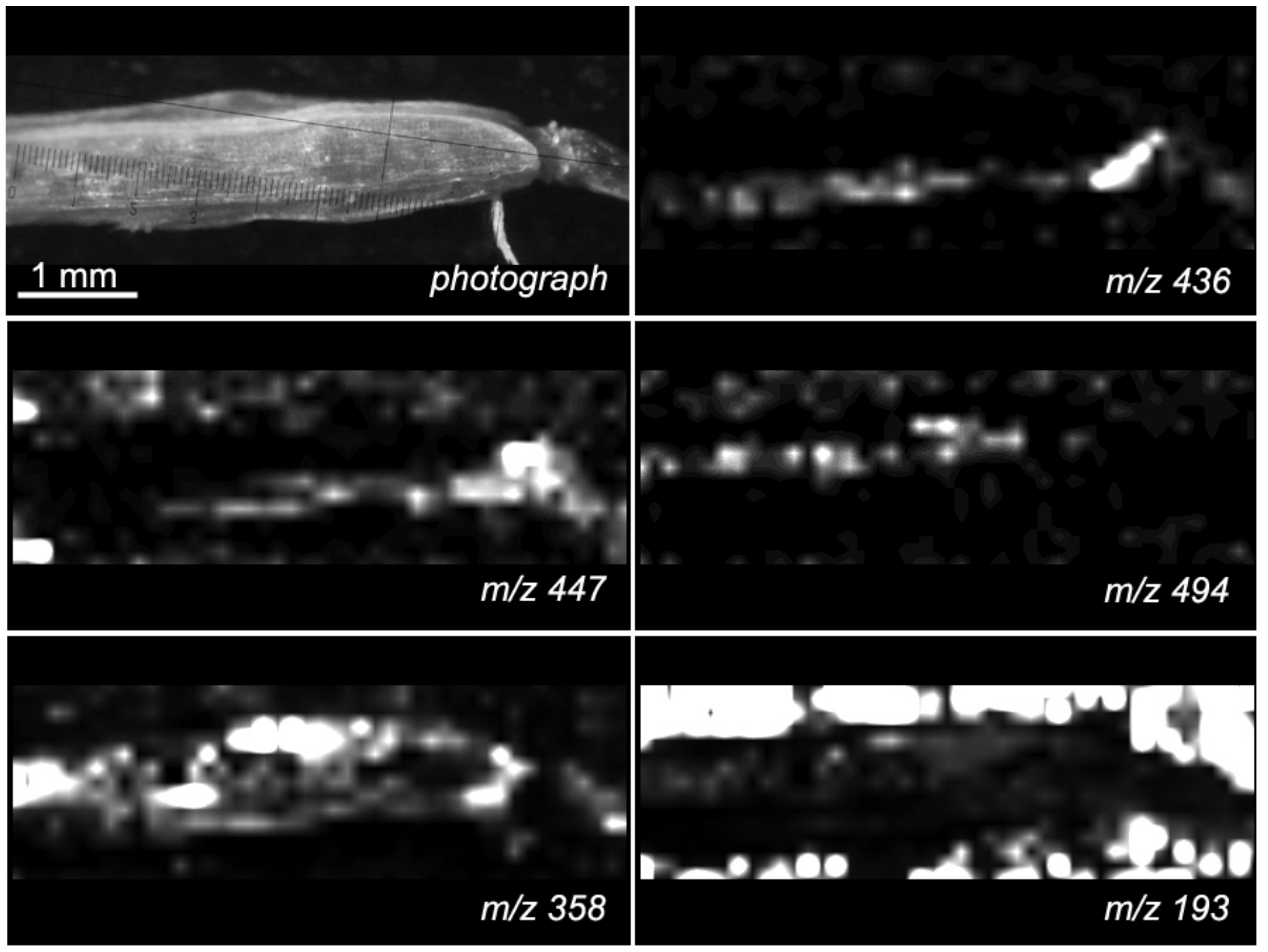
Figure 3.

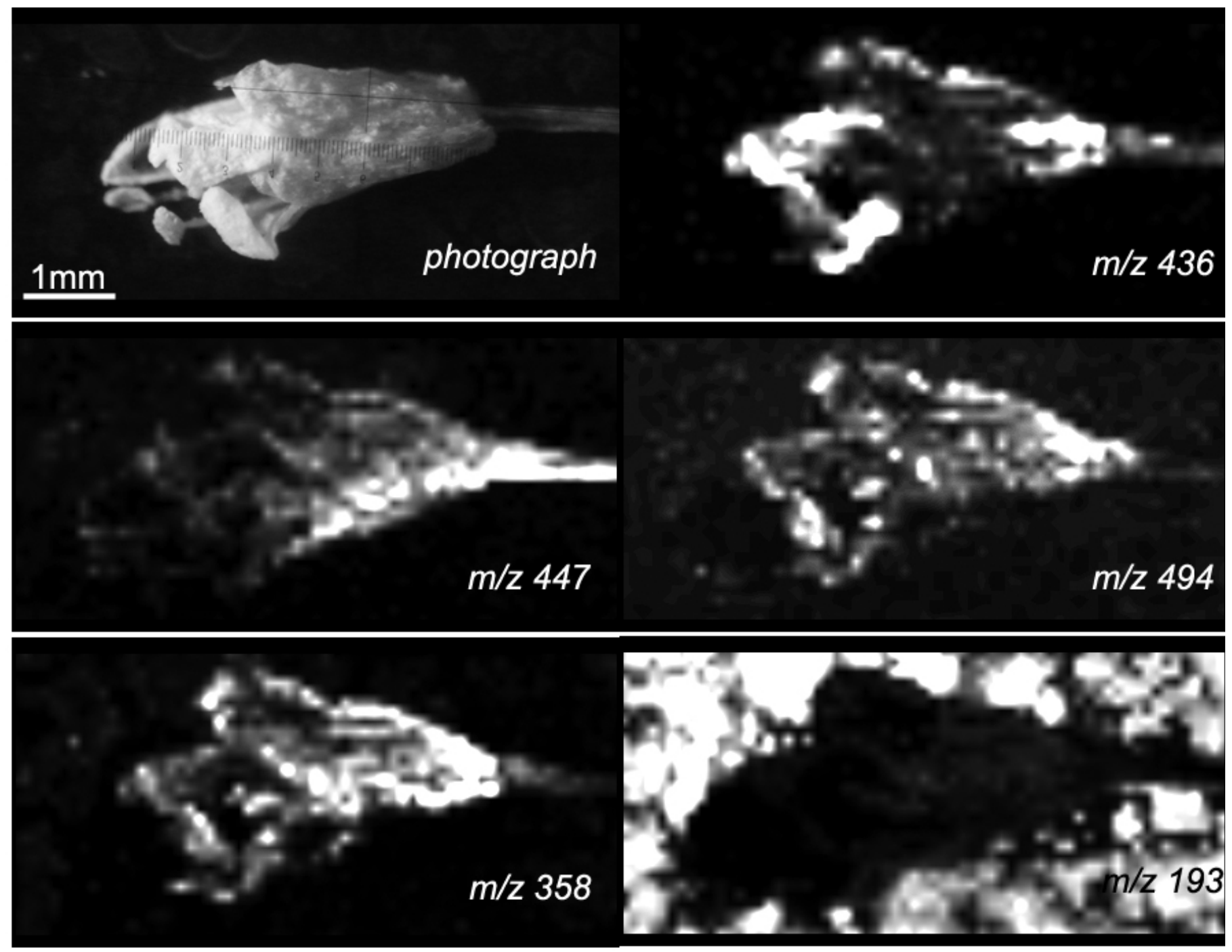


Figure 4.
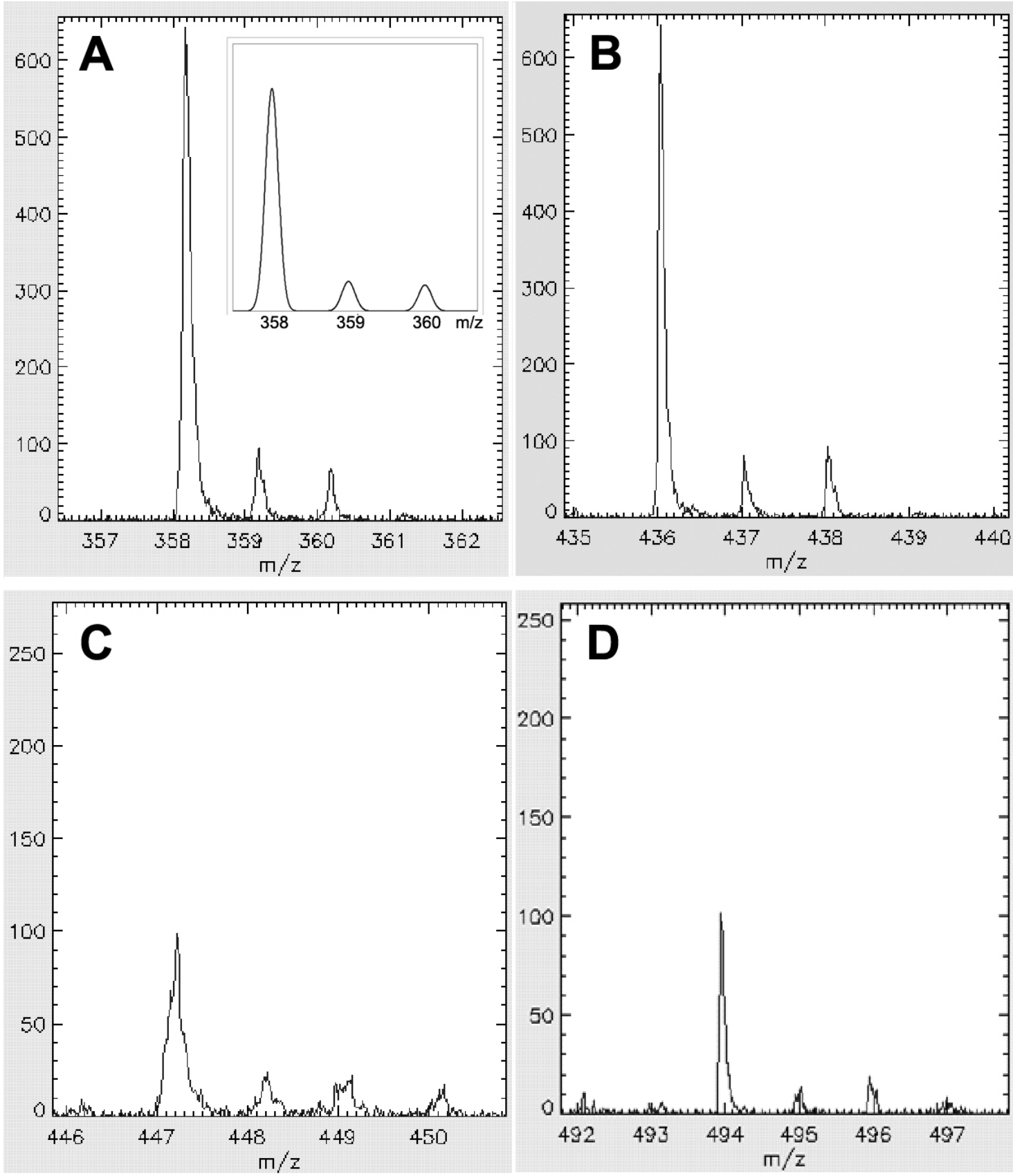


\section{Figure 5}
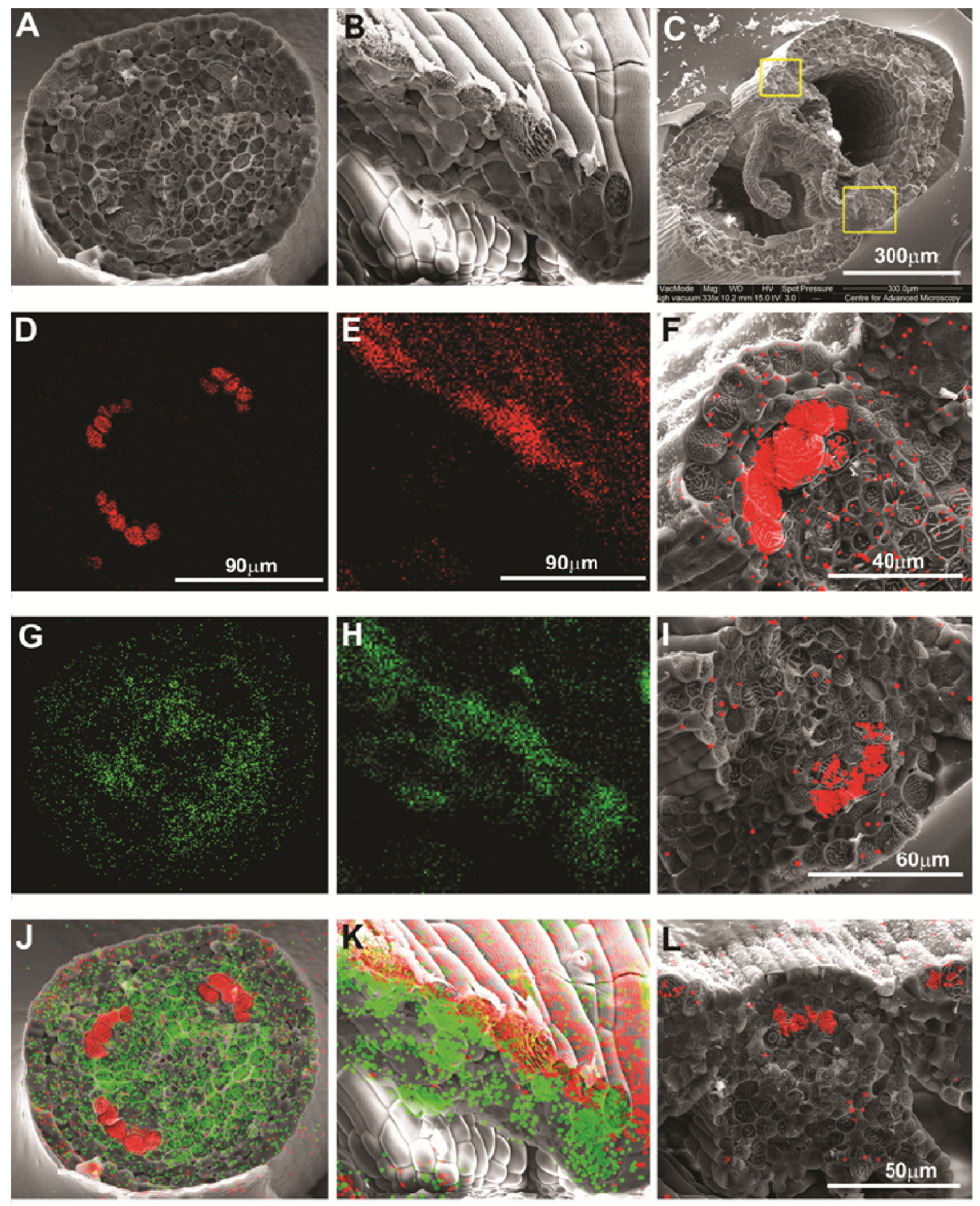
Figure 6.
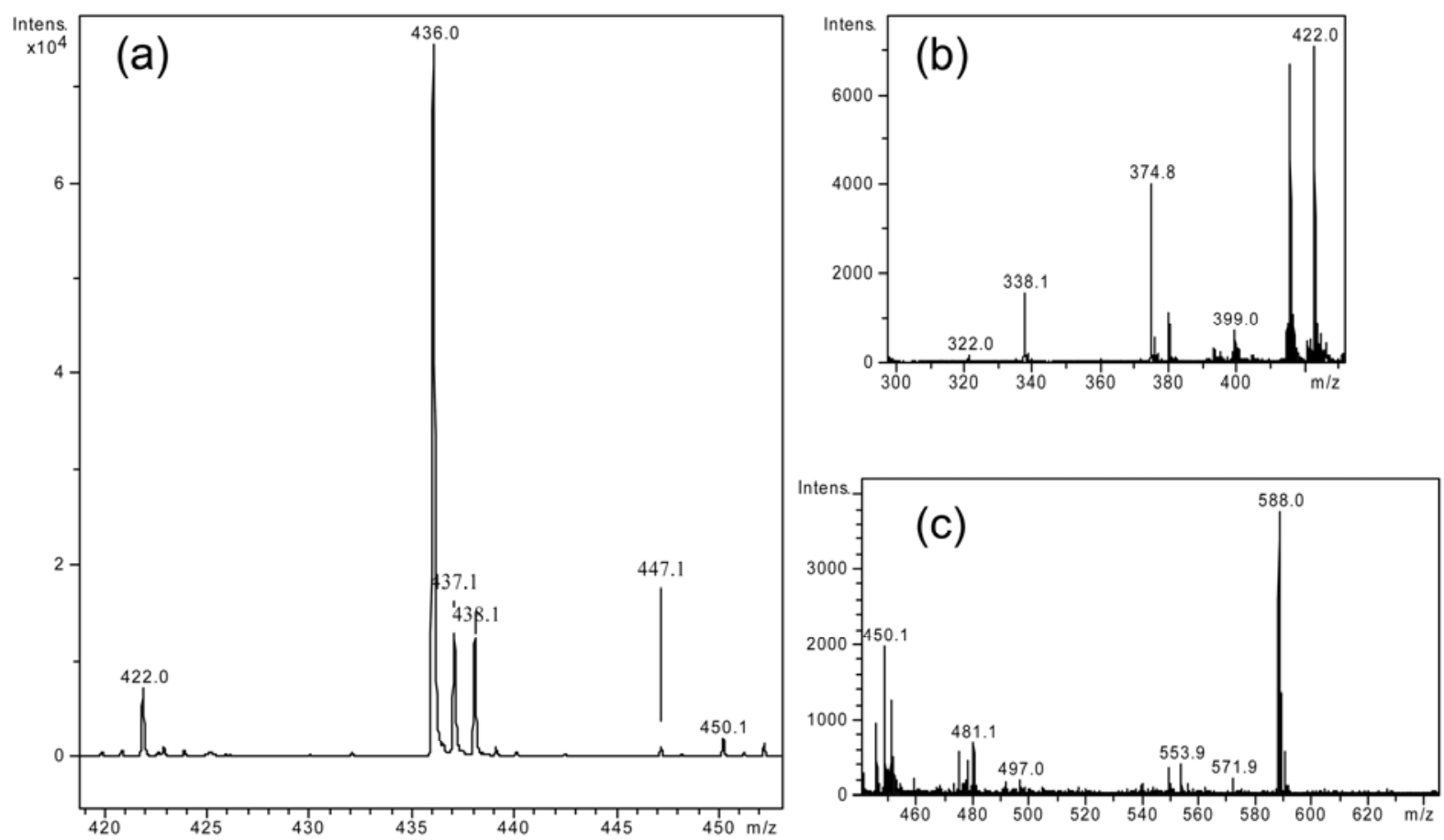